\title{
Practice of and Reflection on Construction of Undergraduate Training Quality Assurance System of Colleges and Universities
}

\author{
Congni Qi \\ Foreign Languages School, Jingchu University of Technology, Jingmen Hubei , 448000, China
}

Key words: Colleges and universities, Undergraduate, Undergraduate training quality assurance system, Practice.

\begin{abstract}
In the new period, with the further promotion of reform of higher education, to construct an undergraduate training quality assurance system has become an important part of the reform of higher education, of certain positive impact on the enhancement of the overall education quality of China. This paper is written, starting with the construction of undergraduate training quality assurance system of Chinese colleges and universities, to put forward suggestions on the construction, with a hope to create good conditions for the construction of undergraduate training quality assurance system of colleges and universities.
\end{abstract}

\section{Introduction}

The state educational departments, based on the needs of reform and development of higher education, have made medium-term and long term education reform and development outlines, explicitly pointing out that further raising education quality should be focused on in the fundamental education reform and development to contribute to the realization of the strategy of invigorating China through science, education and human resource development. At the undergraduate education phase, the measures for raising the education quality include attaching more importance to talent training, actively carrying forward scientific research, and strengthening social service construction. Only by this, high-quality undergraduate talents can be trained, to support the construction of socialist modernization.

\section{Importance of Construction of Undergraduate Training Quality Assurance System to Chinese Higher Education at the Present Stage}

Presently, the talent training quality assurance systems constructed by Chinese colleges and universities based on their conditions essentially are greatly in line with the construction and development of the country. Especially, the state educational department started the undergraduate college teaching evaluation program to respond to the demand for high-quality talent training at the start of the century, which marked that the state involvement in evaluation of talent training of colleges and universities. This program aimed to promote Chinese colleges and universities to make greater achievements in higher education, and train more high-quality talents for social construction in the new era. This program also was questioned by the public. The public doubted that the government sector acted as both organizer and executor in the program meant that both the management and evaluation powers were in the hands of government, and the carrying out of the program was mandatory, so the democracy and scientificity of the program were greatly reduced. Besides, the management organization was bureaucratic and dogmatic to a certain extent, which would hinder the construction and development Chinese colleges and universities. The problems of the program and the questioning of the public certainly affected the effect of evaluation, weakened the effect of teaching evaluation on Chinese undergraduate education development, dampened the 
enthusiasm of other social groups for higher education evaluation and talent training, and even limited the overall improvement of comprehensive quality of Chinese talents. Hence, whereas the national undergraduate college teaching evaluation has ended and it becomes a major trend to implement standardized teaching management inside colleges and universities, the state, to put higher education into full play in high-quality talent training, should mobilize the forces of education to break through the limitations of talent training, and gradually build a quality assurance system conforming to the current needs of social construction and development, so as to lay a solid foundation for undergraduate training for Chinese colleges and universities.

\section{Practice of Undergraduate Training Quality Assurance System Construction of Chinese Colleges and Universities}

\section{Carry the work of training quality assurance system forward}

The undergraduate training quality assurance system of colleges and universities is a part of quality assurance system of colleges and universities. The first job in carrying the construction of quality assurance system forward is to determine the construction content and scope. Specifically, as for the construction of undergraduate training quality assurance system of colleges and universities, the primary task is to guarantee total investment, namely raising the consciousness of scientific and technical workers of colleges and universities in construction of talent training quality assurance system, and then promoting the construction of quality assurance system to go smoothly via the active involvement of talents, to lay a solid foundation for the establishment of undergraduate training quality assurance system of colleges and universities[2]. Meanwhile, stress should be laid on whole process management, namely gradually raising undergraduate training quality through construction and improvement of all links of whole process management, to ensure high quality of all links of talent training. Only by this, complete coverage and whole process promotion of construction of undergraduate training quality assurance system of colleges and universities can be realized, to largely raise the construction level of quality assurance system, create conditions for the optimization of talent training of colleges and universities and training of high-quality talents, and lay a human resource foundation for the optimization of the socialist modernization of China.

\section{Plan process design, and set a rational development goal.}

Presently, preparations such as planning and process setting should be made for the carrying out of construction of undergraduate training quality assurance system of colleges and universities, and the comprehensive quality management theory, higher education theory and theory of human resources administration in colleges and universities should be based on. Only by organically combining these theories and carrying the optimization of talent quality assurance forward, the construction of talent training quality assurance system can receive true support, to guide the optimization of quality assurance system construction. Specifically, planning the design flow in the construction process of undergraduate training quality assurance system of colleges and universities is to sum up the problems encountered during the construction of talent training quality assurance system in combination with the educational management characteristics of colleges and universities, so as to develop projects in relation to the construction of quality assurance system. Then, the tasks of undergraduate training of colleges and universities also are fulfilled based on related projects, to gradually establish corresponding quality management guarantee circulation action mechanism to support the carrying out of undergraduate training.

Meanwhile, for the construction of undergraduate training quality assurance system of colleges and universities, the quality of the construction project of quality assurance system should be observed and measured, and proper quality construction objectives should be set based on the observed results, to provide scientific guidance to the construction of talent training quality assurance system. That's to say, rational development objectives should be emphasized in the construction process of quality assurance system, to scientifically set quality development objectives while 
comprehensively analyzing and researching the management activities and contents based on the focal points of quality assurance system construction, and legal and normative text presentation process should be made to guarantee the realize of objectives. As for the construction of undergraduate training quality assurance system of colleges and universities, rational quality objectives can correctly guide the quality management work, restrict the activities, raise the level of quality management by implementing proper quality standards, and significantly enhance the creativity and constructiveness of undergraduate training of colleges and universities. As for undergraduate education, the objectives of talent training quality can be presented in various ways, including data-based and text-based by text type, fundamental form, competitive type and excellent type by the degree of quality attainment, and subjective feeling type and objective description type by the manifestation of quality objectives, etc[3]. However, in the practice of construction of undergraduate training quality assurance system, there are certain difficulties in the setting of quality objectives. The work of undergraduate training of colleges and universities involves many aspects, the tasks are heavy, the running of related links have certain characteristics and conforms to the personalized rule, and the links are associated with each other. Therefore, the undergraduate education departments of colleges and universities also should analyze these problems in the process of setting the quality assurance objectives of talent training quality assurance system, and actively change their quality concept, to raise the scientificity and authority of quality assurance objectives, provide scientific guidance to the construction of quality assurance system, and lay a solid foundation for the optimization of undergraduate training of colleges and universities.

\section{Promote the standardization and normalization of teaching quality evaluation}

In the process of construction of talent training quality assurance system forward, colleges and universities should carry out quality evaluation based on fact analysis after rationally making quality planning and setting quality objectives, and take measures to promote the standardization and normalization of quality evaluation, to obtain comprehensive objective quality evaluation information to support and guarantee the construction of undergraduate training quality assurance system. Specifically, two aspects should be stressed for promoting the standardization and normalization of talent training quality evaluation. The standardization of quality evaluation involves related properties showed via the quality of the evaluated object, and requires to make provisions to restrict the evaluation implementation process. The focus of standardization of evaluation is to ensure that related evaluation actions can be implemented in strict accordance with the regulations.

As to the undergraduate training quality assurance system of colleges and universities, evaluation is an indispensable link in the process of constructing quality assurance system, refers to activities of observing, information collection, information arrangement and information processing carried out by evaluators over related talent training quality, provides corresponding essential data support to the construction of quality assurance system at the next stage, and enhance the pertinence of quality assurance system construction[4]. Besides, after standardization of quality evaluation is completed, measures should be taken to guarantee the normalization of quality assurance system construction, to create necessary conditions for playing the functions of the quality assurance quality. Generally speaking, the normalization of construction project of quality assurance system mainly involves two aspects, namely guaranteeing the normalized running of the completed projects and enhancing the normalized running state of regular items of talent training quality assurance system construction.

At present, Chinese colleges and universities are exploring the construction of undergraduate training quality assurance system, have not made remarkable achievements yet, and have a long way to go. That's to say, there are bound to be problems from the initial design to the final implementation in the process of quality assurance system construction, the colleges and universities also will encounter various problems even after the quality assurance system is put into use for they are certainly different in undergraduate training, and even the quality assurance system will be doubted by the public if it cannot play a significant role in a short time. Therefore, to give full play to the undergraduate training quality assurance system of Chinese colleges and universities and solve 
various problems occurring in the process of undergraduate training, more attention should be paid to the normalization of the quality assurance system so as to make the quality assurance system be recognized by the public. Only by this, the undergraduate training quality of Chinese colleges and universities can be gradually raised, and more talents will be trained by higher education for social construction.

\section{Comprehensively promote information construction in reliance upon the network}

With the development and the widespread use of information technology, information construction has a huge influence on people's living and production. It has become an inexorable trend to promote colleges and universities to enhance network-based and information construction in the process of talent training quality assurance system construction, which has positive impact on the improvement of talent training efficiency and effect. On this basis, the undergraduate education administration should establish corresponding information sharing platform based on the construction of talent training quality assurance system, and comprehensively promote the construction and development of quality assurance system by virtue of the effect of network information technology of information transmission and amplification, to significantly improve the construction level of quality assurance system[5]. Besides, the construction of undergraduate training quality assurance system of colleges and universities is a demanding work for the personnel maintaining the running of the system. Related teaching staff are hoped to be professional, getting information literacy while improving the professional educating ability, keeping pace with the times to apply information technology in talent training, improving the quality of undergraduate training, and outputting talents for the construction of the talent training quality assurance system.

\section{Conclusion}

To sum up, colleges and universities should actively change their ideas when promoting the construction of undergraduate assurance system, taking measures to promote the optimization of undergraduate training quality assurance system construction, providing corresponding guarantee for the training of undergraduate talents, promoting the undergraduate education quality to significantly rise, and laying a foundation for the sustainable development of colleges and universities and the optimization of high-quality talent training.

\section{References}

[1] Xiao Weihuang. A Study on Composition and Structure of Talent Training Quality Assurance System of Colleges and Universities, Journal of Guizhou Normal College, 2015,31(10):64-70.

[2] Zhou Chuansheng, Liu Junfeng, Zheng Xiumei, et al. Construction of Talent Training Quality Assurance System of Three-full Multi-form Colleges and Universities, Journal of Mudanjiang Normal University (Natural Science Edition), 2014(3):55-57.

[3] Yang Liu. Construction of Talent Training Quality Assurance System of Chinese-foreign Cooperative Colleges and Universities-Wuhan Textile University, Journal of Wuhan Textile University, 2014,27(1):61-64.

[4] Wang Nenghe. A Study on Quality Assurance System of Characteristic Undergraduate Specialty Construction of Local Colleges and Universities, Heilongjiang Researches on Higher Education, 2014(1):157-159.

[5] Wu Lei. Construction of Quality Assurance System of Application-oriented Undergraduate Colleges, Journal of Yibin University, 2013,13(4):93-96. 